\title{
ВЛИЯНИЕ ЦИФРОВОЙ ЭКОНОМИКИ НА ЭКОНОМИЧЕСКОЕ РАЗВИТИЕ В УСЛОВИЯХ ГЛОБАЛЬНОЙ КОНКУРЕНТОСПОСОБНОСТИ
}

\author{
( 2021 Жирова Саида Ахмедовна \\ старший преподаватель кафедры экономики и финансов \\ Кабардино-Балкарский государственный университет им. Х. М. Бербекова, Россия, Нальчик \\ sayida@yandex.ru
}

(C) 2021 Калабекова Лейля Ибрагимовна

кандидат экономических наук, доцент кафедры экономики и финансов Кабардино-Балкарский государственный университет им. Х. М. Бербекова, Нальчик 7369132@mail.ru

\section{(c) 2021 Шумахова Карина Султановна}

кандидат экономических наук, ст.преподаватель кафедры экономики и финансов ИПЭиФ Кабардино-Балкарский государственный университет им. Х. М. Бербекова, Россия, Нальчик karinashumahova@mail.ru

\section{(c) 2021 Аксорова Кристина Хусейновна}

старший преподаватель кафедры биологии, геоэкологии и молекулярно-генетических основ живых систем ИХиБ

Кабардино-Балкарский государственный университет им. Х. М. Бербекова, Россия, Нальчик krismys1207@mail.ru

Цифровизация может иметь различные последствия для рынков труда в развитых странах, цифровые технологии оказывают огромное влияние на трансграничное перемещение производственных площадок, а также технология 3D-печати может изменить мировую торговлю.

Авторы раскрывают вопрос о влиянии цифровизации на развитие международной конкурентоспособности всей мировой экономики и, как следствие, на материальное благосостояние людей. Рассматривается также влияние перехода на цифровую экономику в странах с различным уровнем экономического развития на национальную экономику и последствия такого перехода.

Ключевые слова: цифровизация, международная конкурентоспособность, экономическое развитие, мировая экономика, экономическое развитие.

Цифровая экономика прочно входит в нашу жизнь. Развитие цифровой экономики становится в современных условиях важным и приоритетным направлением, хотя и является виртуальной. Цифровизация позволяет развить деятельность бизнес-структур, способствует разработать и внедрить новые модели бизнеса, объединяет усилия для создания инноваций/ Применение цифровых технологий позволяет увеличить инвестирование, способствует улучшению поиска сотрудников, новых партнеров, ресурсов, а также рынков сбыта. Также они имеют важное значение при обучении сотрудников и обмене знаниями, помогают при реализации инновационных идей в различных сферах. Большинство мировых государств берут на себя управление перехода на цифровую экономику на национальном уровне.

По мнению экономистов разных стран, цифровые технологии будут в ближайшем будущем все большее влиять на развитие производственных процессов. Как следствие, велика вероятность капиталоемкости технологичности производственных процессов во всех странах мира независимо от уровня экономического развития.

Возрастающая капиталоемкость и технологичность производства влияет на конкурентоспособность между всеми странами мира следующим образом:

- В случае увеличения замены человеческого труда роботами, компьютерами и машинами, развивающиеся страны с высоким уровнем трудоемкости теряют свое решающее конкурентное преимущество, а именно - дешевую рабочую силу. 
- При этом богатые страны с высоким уровнем развития промышленности улучшают свое экономическое состояние в связи с возможностью улучшения (увеличения) финансирования своих затрат на цифровую трансформацию.

В ближайшее время на уровень международной конкурентоспособности отдельных экономик будет иметь огромное влияние быстрота внедрения цифровых технологий в производственные процессы на уровне национального государства. При этом необходимо отметить, что данная цифровая трансформация будет зависеть от наличия у страны необходимые ресурсы для такой трансформации.

Уровень экономического развития имеет значительное влияние на доступные ресурсы. Чаще всего это характеризуется уровнем реального валового внутреннего продукта на душу населения. Используя этот показатель, мир условно делится на три основные группы стран - в примерном и грубо упрощенном виде.

Первую группу составляют западные индустриальные экономики.

На современном этапе учитывая уровень ВВП на душу населения, то можно отметить самый высокий доход на душу населения в промышленно развитых западных странах.

При дальнейшем продвижении цифровых технологий в экономике в целом такие страны смогут усилить свою конкурентоспособность. Как следствие. Будет наблюдаться (например, в США) дальнейшее увеличение ВВП на душу населения.

При невозможности продвижения цифровой трансформации, у промышленно развитых стран конкурентоспособность будет сильно снижаться. Такое положение будет характерно таким экономически слабым странам как Греция, Италия. Особенно при наличии огромной внешней задолженности. Высока вероятность попасть в данную группу и у стареющих обществ в силу снижения инновационной силы, а также производительности стареющего общества.

Вторую группу стран составляют азиатские страны с развивающейся экономикой.

Большинству стран Азии с формирующейся рыночной экономикой характерен за последние двадцать лет сильный экономический рост. Это становится причиной наличия у странпредставительниц данной группы достаточных финансовых ресурсов для цифровой трансформации. Примером такого резкого экономиче- ского роста служат Китай, Южная Корея, Индонезия, Таиланд и Тайвань.

Третью группу составляют африканские развивающиеся страны.

Страны данной группы имеют двоякое состояние.

Африканским странам характерно наличие молодого и растущего населения, что позволяет при внедрении цифровой инфраструктуры и продвижении всего сектора образования обеспечить сильный экономический рост [3]. При этом для некоторых из этих стран возможен экономический скачок, минуя технологический этап. Экономисты приводят следующий пример. Сoздание сети мобильной связи при ее отсутствии в слаборазвитой стране при отсутствии обычной стационарной телефонной линии, позволяет выйти такой стране на один технологический уровень с промышленно развитой страной.

Для слаборазвитых бедных экономик такой переход на цифровые трансформации может быть проблематичным в связи с отсутствием ценного сырья и доступа к рынку капитала. Такая ситуация может привести к еще большему экономическому отставанию в связи с резким снижением конкурентоспособности.

При высоком уровне международной конкурентоспособности велика вероятность процветания населения государства, а также увеличивается возможность входа на международный рынок отечественных компаний, а также реализовывать продукцию на национальном рынке. Такая ситуация положительно сказывается на экономике страны, так как создаются новые рабочие места и сотрудники получают свои доходы.

Повышение конкурентоспособности позволяет странам увеличить производство товаров и услуг, а, следовательно, валовой внутренний продукт, в том числе и валовой внутренний продукт на душу населения. В случае отказа от успешной цифровой трансформации, страны теряют возможность роста благосостояния населения страны.

Очевидно, что цифровая трансформация экономики любого государства позволяет повысить обеспеченность и благосостояния страны.

С точки зрения будущего развития демографических изменений, глобализации и технологических изменений или цифровизации особое значение имеют пять тенденций развития:

1. Само по себе мировое демографическое 
развитие ведет к перераспределению глобального процветания. По крайней мере, можно ожидать тенденции к приближению заработной платы к среднемировому уровню. То же самое и с ВВП на душу населения. В то время как развивающиеся рынки, особенно в Азии, могут ожидать увеличения индивидуального благосостояния, измеряемого таким образом, из-за этого в развитых промышленно развитых странах вероятно снижение реальных доходов. Африка грозит отставать еще дальше в экономическом отношении, если ей не удастся создать достаточное количество рабочих мест для своего быстрорастущего населения.

2. Внутри группы промышленно развитых стран международное конкурентное давление значительно возрастет в странах с наиболее сильно стареющим населением (Япония и Германия). Эти страны сталкиваются с еще большей потерей международной конкурентоспособности, чем другие промышленно развитые страны, включая связанную с этим безработицу и потерю доходов.

3. Технический прогресс - и, прежде всего, прогрессирующая цифровизация - в целом может улучшить ситуацию с предложениями людей товарами и услугами. Однако возможные тенденции к монополизации в отдельных частях цифровой экономики могут помешать использованию этого потенциала, если монополисты используют свою рыночную власть в ущерб потребителям и сотрудникам.

4. Последствия цифровизации для рынка труда непоследовательны, поскольку цифровой технологический прогресс приводит как к разрушению рабочих мест, так и к созданию рабочих мест. Однако в краткосрочной перспективе (то есть в течение следующих 10-15 лет) значительная чистая потеря рабочих мест маловероятна. В долгосрочной перспективе (например, начиная с 2040/50 гг.), Эффект разрушения рабочих мест может перевесить потерю рабочих мест.

5. В любом случае можно предположить, что человеческие ресурсы будут все больше заменяться капиталом и технологиями в производственных процессах - особенно в промышленно развитых странах, но также и во всем остальном мире. Для международного разделения труда это может привести к тенденции к «инсорсингу», чему может способствовать, прежде всего, технология 3D-печати. Помимо этого, распределение дохода сместится в пользу фактора производства капитала. В промышленно развитых странах это также означает, что доля дохода, получаемого от оплачиваемой работы, в общем социальном доходе будет продолжать снижаться, особеннодля низкоквалифицированных работников рабочие. Если человеческие ресурсы потребуются в меньшей степени в производственных процессах, многие развивающиеся страны потеряют одно из своих ключевых конкурентных преимуществ, а именно низкую заработную плату.

По мнению Д-р Тисс Петерсена, ожидаемые структурные изменения в экономике означают значительные изменения для людей, что обычно связано с высокой степенью неопределенности. Поэтому, особенно во время серьезных структурных изменений, надежные системы социального обеспечения должны обеспечивать людям безопасность, которая им необходима для активного формирования структурных изменений, вместо того, чтобы просто позволять им происходить с ними или даже желать их предотвратить. Это становится все труднее для стареющих промышленно развитых стран, которые в долгосрочной перспективе теряют свою международную конкурентоспособность и вынуждены тратить значительную часть своих государственных доходов. Однако, по мнению Д-р ТиссПетерсена, без этого «пояса социальной защиты» существует риск усиления социальной напряженности, что может привести к усилению политической поляризации. Он приводит следующую схему (на рисунке 1).

Цифровая экономика меняет привычные модели отраслевых рынков, повышает конкурентоспособность участников рынков [2]. Наличие конкуренции на рынке товаров или услуг требует от нее обеспечения определенной конкурентоспособности, что возможно при продвижении цифровизации на мировом уровне.

Цифровое пространство предоставляет огромное количество возможностей как в экономическом, политическом, так и в социальном аспекте, трансформируя поведение человека. Помимо очевидных плюсов есть сложности и опасности, многие из которых пытается урегулировать государство, за счет юридического ресурса, другие необходимо контролировать самим людям. Тогда плюсов будет значительно больше, а опасностей - меньше. 


\section{Negative economic effects of globalization and technological progress as a breeding ground for populism}

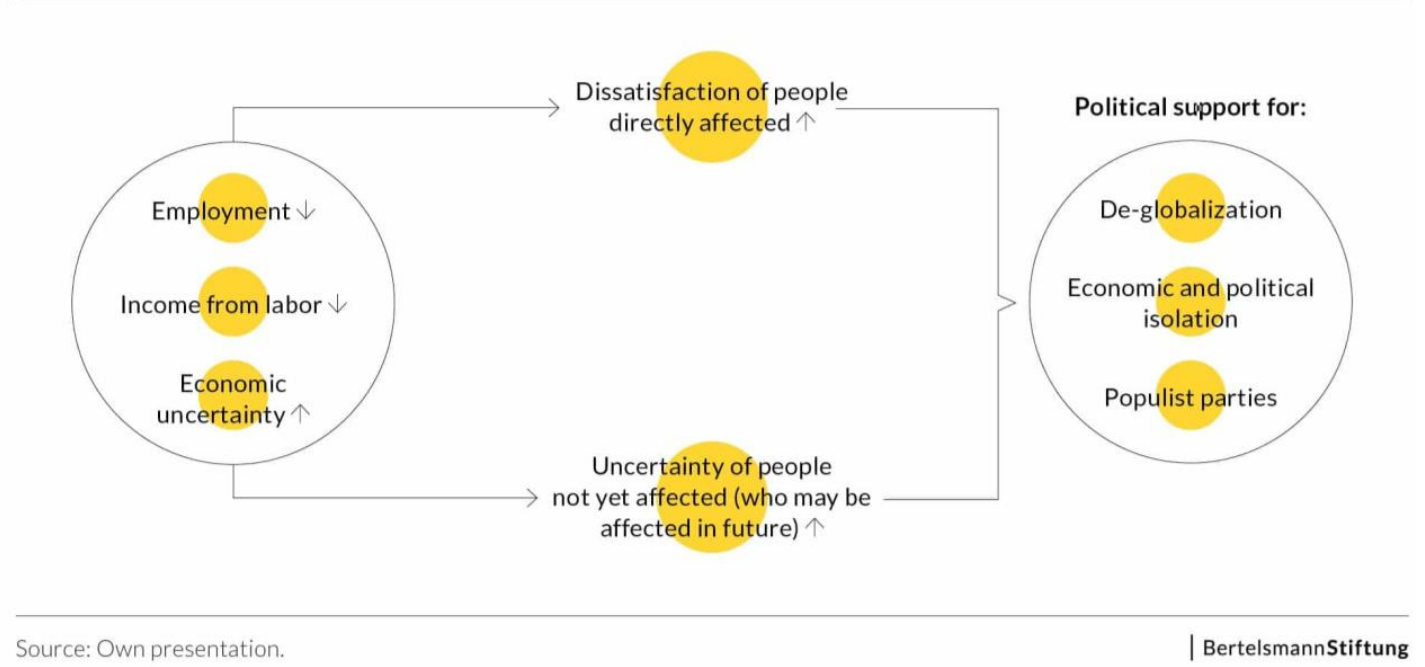

Рисунок 1. Пояс социальной защиты [2]

\section{Библиографический список}

1. Д-р Тисс Петерсен Цифровая экономика: как цифровизация меняет глобальную конкурентоспособность и экономическое процветание?// [электронный ресурс], Режим доступа: https://ged-project.de/digitizationand-innovation/digital-economy-how-is-digitalization-changing-global-competitiveness-and-economicprosperity/ Дата обращения: 20 марта 2021.

2. Бабкин А.В., Чистякова О.В.Цифровая экономика и ее влияние на конкурентоспособность предпринимательских структур // Российское предпринимательство. - 2017. - Том 18. - № 24.- C. 4087-4102.- doi: 10.18334/rp.18.24.38670

3. Текуева М.Т., Макшаева М.И., Дохова 3. З. Цифровая экономика в условиях глобальной конкурентоспособности и экономического развития// Цифровая экономика: тенденции и перспективы развития в России и мире: сборник материалов конференций / гл. ред. М. Т. Текуева.- Нальчик: Binding2016, 2021.- 487 с. Электронное издание.- ISBN 978-5-906771-85-8. 